\title{
Improving the Curriculum with Ethics: Gaps between Perceived Ethical Challenges of Practitioners and Educators
}

\author{
Diane M. Dolezel ${ }^{1, *}$ \& Eileen E. Morrison ${ }^{2}$ \\ ${ }^{1}$ Department of Health Information Management, Texas State University, USA \\ ${ }^{2}$ School of Health Administration, Texas State University, USA \\ *Correspondence: Department of Health Information Management, Texas State University, USA. Tel: \\ 1-512-245-8242. E-mail: dd30@txstate.edu
}

Received: February 15, 2017

Accepted: March 2, 2017 Online Published: March 10, 2017

doi:10.5430/jct.v6n1p45

URL: https://doi.org/10.5430/jct.v6n1p45

\begin{abstract}
Health information management (HIM) professionals must address ethical challenges in their role as guardians of patients' personal information and organizations' proprietary information. Because of this need, HIM educators strive prepare their students to address these challenges. Unfortunately, little evidence exists about specific areas of applied ethics that should be part of the HIM curriculum. The purpose of this exploratory study was to determine the ethical issues relevant to the current practice in Health Information Management. In particular, the study aimed to determine if the perceptions of HIM educators and practitioners regarding HIM workplace ethical issues were consistent, and to identify gaps in perceptions. The researchers distributed a survey to HIM educators and HIM practitioners, 12 educators and 25 practitioners completed their surveys. Thematic content analysis indicated a divergence of themes among these groups. Overall, educators' responses reflected general knowledge areas whereas practitioners' comments were more specific in terms of ethics concerns. The study findings indicated a gap in perceptions signalling a need for increased communication regarding applied ethics in HIM practice so that curriculums could reflect both theory and application.
\end{abstract}

Keywords: health information management; health informatics; workplace; ethics; higher education

\section{Introduction}

According to the AHIMA Code of Ethics health information management (HIM) professionals serve as guardians of patients' personal information and organizations' proprietary information (American Health Information Management Association, 2011). In this role, they secure the confidentiality of patients and organizational information. However, with the changes in the healthcare system, this duty becomes increasingly more challenging (Layman, 2008; AHIMA House of Delegates, 2008; American Health Information Management Association, 2010). How can educators better prepare graduates to be ready for their role as guardians and the ethics challenges this role represents?

HIM educators must not only teach current ethics content that applies to their field. They also must prepare students for future ethics challenges, as they become part of the rapidly changing Affordable Care Act (ACA) era (Patient Protection and Affordable Care Act, 2010). To address this responsibility, HIM educators need to communicate with practitioners and obtain real world examples of ethical issues. Upon obtaining such information, educators can teach students to practice using ethics tools and reasoning with realistic scenarios.

In addition to obtaining content information, HIM educators must create a curriculum that addresses national standards in their field. These standards include the ability for graduates to analyze ethics issues and make appropriate decisions. Compliance with the standards requires educators to maintain currency in the application of ethics in the practice of health information management. In a changing healthcare environment, maintenance of currency requires knowledge and understanding about the actions taken by practitioners. This exploratory study assists in the process of maintaining currency with respect to the practice of ethics in health information management settings.

Therefore, this study serves as a first step in identifying the differences between perceptions of ethics among HIM practitioners. It also seeks to identify similarities and differences in HIM educators' and HIM practitioners' perceptions of significant ethical issues. Based on data analysis, the authors will provide recommendations for the 
improvement of HIM students' ethics readiness and for improvement in the curriculum with respect to practical ethics.

\subsection{Ethical Concepts in Healthcare}

The term ethics comes from the Greek word ethos, which denotes letting one's conscience be one's guide when considering what action to take in each situation (Mcway, 2016). In the HIM field, ethics refers to the study of "moral principles, theories, and values; in healthcare, a formal decision-making process for dealing with the competing perspectives and obligations of the people who have an interest in a common problem" (AHIMA 2014, p. 56). In healthcare, commonly referenced ethical concepts include autonomy, beneficence, nonmaleficense, and justice (Harman \& Cornelius, 2015).

Autonomy is the freedom of individuals to control their own behavior (AHIMA, 2014, p.14). One could demonstrate autonomy by meeting the requirements to obtain the patient's informed consent before surgery and by honoring the right of a patient to refuse treatment (Layman, 2008). Beneficence refers to providing healthcare services in a manner that provides positive health outcomes while minimizing the potential for patient harm (Oachs \& Waters, 2016). An example of beneficence in HIM is safeguarding the patient's protected health data. It also includes ensuring that the availability of data in a complete, current, accessible, and easily usable format for healthcare decision-making (Cellucci et al. 2011; Layman, 2008). Conversely, nonmaleficence is not causing unnecessary harm. In the healthcare informatics arena, this necessitates providing secure data storage, routine backups and routine software updates. Healthcare organizations demonstrate justice by providing equal treatment for all patients and working to increase healthcare access for disadvantaged patients (Harman \& Cornelius, 2015).

\subsection{Ethical Decisions in Healthcare}

Ethical decision-making in healthcare can be easy or difficult. Many people tend to base their ethical decisions on what they have been taught by parents, friends, teachers, church members and other groups. Therefore, their ethical decisions are easy to make, such as those based on what they view as morally unacceptable behavior. Other ethical decisions involve strong personal preferences and differing cultural views that complicate the process. Finding the most equitable answers in the latter cases requires a strong moral compass, in depth consideration of the issues, and putting aside personal predilections (AHIMA, 2014, p. 56; AHIMA Professional Ethics Committee, 2013).

Harman and Cornelius (2015) offer guidance on how to reach fair ethical decisions by utilizing their matrix, which considers the question, the facts, the values, stakeholders, choices, and justifications for the choices

Several factors complicate the ethical decision making process. First, every day healthcare practitioners must deal with a cross section of cultures, religions, educational levels, socioeconomic levels and moral systems that are found among patients and coworkers (Aulisia, 2016; Oachs \& Watters, 2016). This cultural diversity increases the difficulty of arriving at ethical decisions deemed acceptable to all participants. Second, the introduction of information technology into the healthcare arena has increased the availability of healthcare data. As an illustration, there is now widespread usage of electronic health records, personal health records, mobile devices, patient portals, and medical monitoring devices that store data locally. Unfortunately, the increase in information technology has generated new ethics issues surrounding the need to protect personal health information versus the legal rights of patients, insurance companies, business partners, and other authorized users to access that data (HIMSS 2016; HIPAA 1996). Specifically, the increased data availability makes it harder to protect the data from unauthorized use, corruption, or medical identity theft (Oachs \& Watters, 2017). Moreover, this new technology comes with its own potential for errors related to prepopulating erroneous data, failing to check previous work, and the degradation of the patient-physician relationship (Dahnke, 2013). Similarly, the use of mobile devices is problematic because these devices retain healthcare data in non-secure environments (e.g. cellphones, medical devices, patient portals) that are difficult to protect from malicious agents (HIMSS, 2011).

Examples of unethical behavior in HIM include allowing a doctor to document on a discharged patient's chart to cover up a mistake on his or her part and releasing information to unauthorized individuals. They also are demonstrated by taking paper charts home to for review, billing twice for the same procedure, billing at higher code levels than justified by the treatment provided, and employing a coder who has not passed the coding certification exam. Crawford (2011) gives examples of three ethics complaints that were considered by the AHIMA ethics committee. These cases dealt with the assignment of higher billing codes not justified by the service provided, failing to support the staff's professional development needed to maintain their certifications, and under reporting the number of delinquent charts to avoid penalties.

\subsection{Importance of Ethics in Healthcare Education}

Healthcare professionals must make ethical decisions every day during the performance of their professional duties. 
Healthcare educators must prepare their students to address these challenges through classroom and field-based activities. For example, there has been an increase in ethical issues as the U.S. healthcare system works overtime to care for greater numbers of patients from more diverse populations (Buelow, Mahan, \& Garrity, 2010). Given this situation, Buelow et al. (2010) stressed that educators of health professionals need to give their students opportunities to explore different views on the application of ethics in real world situations. In addition, they encouraged educators to increase students' competency in the knowledge, skills, and attitudes needed to address ethical issues that may challenge their perspectives on moral reasoning.

Currently, no research studies were found addressing ethics in HIM education. However, a few studies have been conduct in other healthcare fields that consider the value of ethics education and ethics in healthcare. For example, Ulrich et al. (2014) conducted a retrospective analysis data of collected from nurse practitioners and physician assistants in 2002 to 2003 to explore the relationships of ethics preparedness and ethics confidence on self-reported perceived quality of care. Results indicated that participants who reported higher levels of ethics preparedness and ethics confidence indicated higher perceptions of their ability to deliver quality care. Ulrich et al. (2014) recommended the design of ethics classes to inform students of practice challenges, the realities of patient-provider communications, and the need for supportive interprofessional collaboration.

According to Budinger and Budinger (2006), while IT has many benefits for patient care and healthcare management, it also poses ethics concerns for privacy and confidentiality. Ethical concerns may arise with processes related to data collection, data storage, data mining, and employee access to healthcare data or to specific areas of healthcare facilities. The prevention of viruses, fraud, and hacking are emerging as HIT ethics challenges (Budinger \& Budinger, 2006). Based on these areas of prevention, HIT educators must ensure that their students understand the concepts of justice and duty, and the principles of fidelity and beneficence as they apply to HIT workplace issues. They must also demonstrate the ability to apply ethical reasoning and the ability to balance duty with benefit when resolving ethical dilemmas in a classroom or clinical setting. In a related study, Dhanke (2013) recommended ethics education for health administration students as one way for them to combat negative images of their role. This knowledge could also assist them to realize their potential as ethical administrators who are capable of higher order ethical reasoning.

Grady et al. (2008) evaluated practicing nurses and social workers in the U.S. regarding self-reported levels of ethical stress, their workplace ethical climate, and the ethical resources they used at work to determine if they felt their education prepared them for workplace ethical realities. Results showed positive correlations between having ethics education (in class or at work), higher reported levels of ethical confidence at work, and increased use of ethical resources. A related survey study of Bachelor of Science nursing students determined that students who completed a problem based ethics module, comprised of three realistic nursing practice ethical scenarios, showed a high level of acceptance of the ethical theories and a high level of perception of the theories as being useful in practice (Monteverde, 2014).

\subsection{Ethics in the HIM Curriculum}

In a recent article, Cellucci, Lawman, Campbell, and Zeng (2011) discussed changes in healthcare including the ACA, which produced an increased need for information system (IS) professionals. Cellucci et al. (2011) include content for IS curriculum that comprises courses in ethics, and a discussion of ethical issues and codes. In addition, they stress the application of ethics in the workplace and provide teaching methods and examples. Harman and Cornelius (2015) begin their textbook with a discussion of ethical issues for IS professionals including dealing with vendors, coding, and sensitive information. They also stress values and professionalism as part of an HIM ethics framework for professionals. Their text supports applied ethics as a concern for both practitioners and educators. Lieneck (2014) includes the pressure to balance the cost of HIT systems implementation with the cost of providing care as an ethical issue for health care and HIT. There may be ethics concerns because of the need to balance the costs of system implementation with the cost of providing patient care.

Anderson (2004) recommends that HIM and HIT programs provide students with opportunities to engage in moral reasoning and analysis based on principles such as autonomy and patient justice. He gives examples of issues that require preparation in selecting best practices that are also ethically sound. These examples include breeches of security, privacy violations through selling patient data, and access to sensitive information. Given the potential for ethical issues in HIM practice, the author suggests a need to strengthen the HIM curriculum and include situations that allow application of ethics decision-making models.

Are HIM educators providing students with relevant ethics dilemmas for analysis? Do HIM educators and HIM practitioners agree on the importance of ethical issues? This study was a first step in determining if there is a difference in perceptions of ethical issues between practitioners and educators. It offers a methodology for analyzing this 
difference and recommendations for utilizing the data for educational improvement in ethics.

\subsection{HIM Curriculum Requirements}

The Health Information Management department at the study site is an accredited BSHIM program. Graduates of the BSHIM program are eligible to take the American Health Information Management (AHIMA) Registered Health Information Administrator Practice (RHIA) credentialing exam. The exam evaluates students' knowledge in the AHIMA domains of learning that will compose the national RHIA exam. Achievement of this credential is essential to job success. The content of this test is divided into domains of learning (e.g. ethics, healthcare statistics) and these domains drive both the mapping of course objectives to a given course and the departmental monitoring of the levels of learning set forth across the curriculum. Monitoring these levels helps to ensure that the HIM curriculum content assesses learning at the correct level.

The first time pass rates on the RHIA exam are one of the criteria for program accreditation. Exam scores are used to evaluate the current students' potential for passing the RHIA exam and to evaluate the department's success in preparing students for the exam. This pass rate is very important to the profession as well because there is a shortage of credentialed professionals in the workforce.

Published annually, the RHIA exam results are disseminated to students and to HIM Department chairs. The results serve as a program benchmark because the exam reports contain statistics comparing students' average scores to the national average scores for each domain. Accordingly, HIM department chairs across the U.S. scrutinize this benchmarking data and may take remedial action if their students display scores lower than the national average.

At the curricular level, course content is reviewed annually to confirm that it still matches the content and Bloom's level set for in the Commission on Accreditation for Health Informatics and Information Management Education (CAHIIM) Curricular Requirements for BSHIM program accreditation. It should be noted that CAHIIM uses their own Bloom's Taxonomy: Revised Version. For example, CAHIIM documentation for Blooms Level 5 Analyzing presents the description, "Can the student justify a stand or decision, or judge the value of?" Similarly, Blooms Level 6 Creating is presented as, "Can the student create a new product of point of view?" See Table 1 for examples of curriculum requirements related to ethics.

Table 1. CAHIIM Curriculum Requirements - AHIMA 2011 Curriculum Competencies and Knowledge Clusters for HIM Education at the Baccalaureate Degree Level

\begin{tabular}{|c|c|c|}
\hline Entry Level-Competencies & $\begin{array}{l}\text { Required } \\
\text { Bloom's } \\
\text { Taxonomy } \\
\text { Level }\end{array}$ & $\begin{array}{l}\text { Curricular Considerations - topics programs may } \\
\text { use to guide students to achieve the competency at } \\
\text { the required Bloom's taxonomy level }\end{array}$ \\
\hline \multicolumn{3}{|l|}{ Subdomain VI.H. Ethics } \\
\hline $\begin{array}{l}\text { 1. Comply with ethical standards of } \\
\text { practice }\end{array}$ & 5 & $\begin{array}{l}\text { * Professional ethics issues; Ethical decision } \\
\text { making process; AHIMA Code of Ethics; Patient } \\
\text { rights; Patient safety }\end{array}$ \\
\hline 2. Evaluate the culture of a department & 5 & N/A \\
\hline $\begin{array}{l}\text { 3. Assess how cultural issues affect health, } \\
\text { healthcare quality, cost, and HIM }\end{array}$ & 5 & $\begin{array}{l}\text { * Healthcare professionals and cultural diversity; } \\
\text { Cultural competence and self-awareness; } \\
\text { Assumptions, biases, and stereotypes }\end{array}$ \\
\hline \multirow[t]{2}{*}{$\begin{array}{l}\text { 4. Create programs and policies that } \\
\text { support a culture of diversity }\end{array}$} & 6 & $\begin{array}{l}\text { *Diversity awareness training programs: age, race, } \\
\text { sexual orientation, education, work experience, } \\
\text { geographic location, and disability }\end{array}$ \\
\hline & & $\begin{array}{l}\text { * Regulations such as Americans with Disabilities } \\
\text { Act (ADA) and Equal Employment Opportunity } \\
\text { Commission (EEOC) }\end{array}$ \\
\hline
\end{tabular}


Class assignments designed by the course instructor are utilized to meet the curricular requirements. Students enrolled in the legal aspects of HIM class study the ethical decision making process and then they work in groups to apply this process to selected case studies. The instructor also has them students write a paper discussing workplace regulations designed to foster ethical workplace treatment for everyone, such as the Equal Employment Opportunity Commission and the Americans with Disabilities Act. The leadership class has an assignment to write a paper describing how they would design a diversity awareness (age, race, sexual orientation, education, etc.) training program; the paper is then presented to the class.

\subsection{Research Questions}

Given the importance of preparing HIM students to face the ethical challenges of the workplace, this exploratory study sought to answer the following research questions:

1. What are the major ethics issues for health information management as perceived by HIM practitioners?

2. What are the major ethics issues for health information management as perceived by HIM educators?

3. What are the differences in perceptions of major health information ethics issues between HIM practitioner and educators?

\section{Method}

The purpose of this exploratory study was to determine the ethical issues relevant to the current practice in Health Information Management. In particular, the aim of the study was to determine if the perceptions of HIM educators and practitioners regarding HIM workplace ethical issues are consistent, and to identify gaps in the perceptions of these two groups. The researchers, who represent two healthcare college departments at the study site, obtained approval from the Institutional Review Board of the study university. They collected their data using a survey instrument designed by the researchers. Data obtained was analyzed using SPSS Version 23 and NVivo 10 qualitative data analysis software (SPSS, 2016; Green \& Salkind, 2013; QSR International Pty Ltd., 2012).

\subsection{Participants}

Participants in the study were a sample of convenience to reflect educators in HIM and HIM practitioners. The researchers selected the sample for educators using a public online listing of accredited BSHIM programs in the United States provided by the Commission on Accreditation for Health Informatics and Information Management Education (CAHIIM) (CAHIIM, 2016). This list included program chairs who were used to represent the educator component of the study. The researchers identified the sample of practitioners from alumni of the BSHIM program at the study site.

\subsection{Instrument}

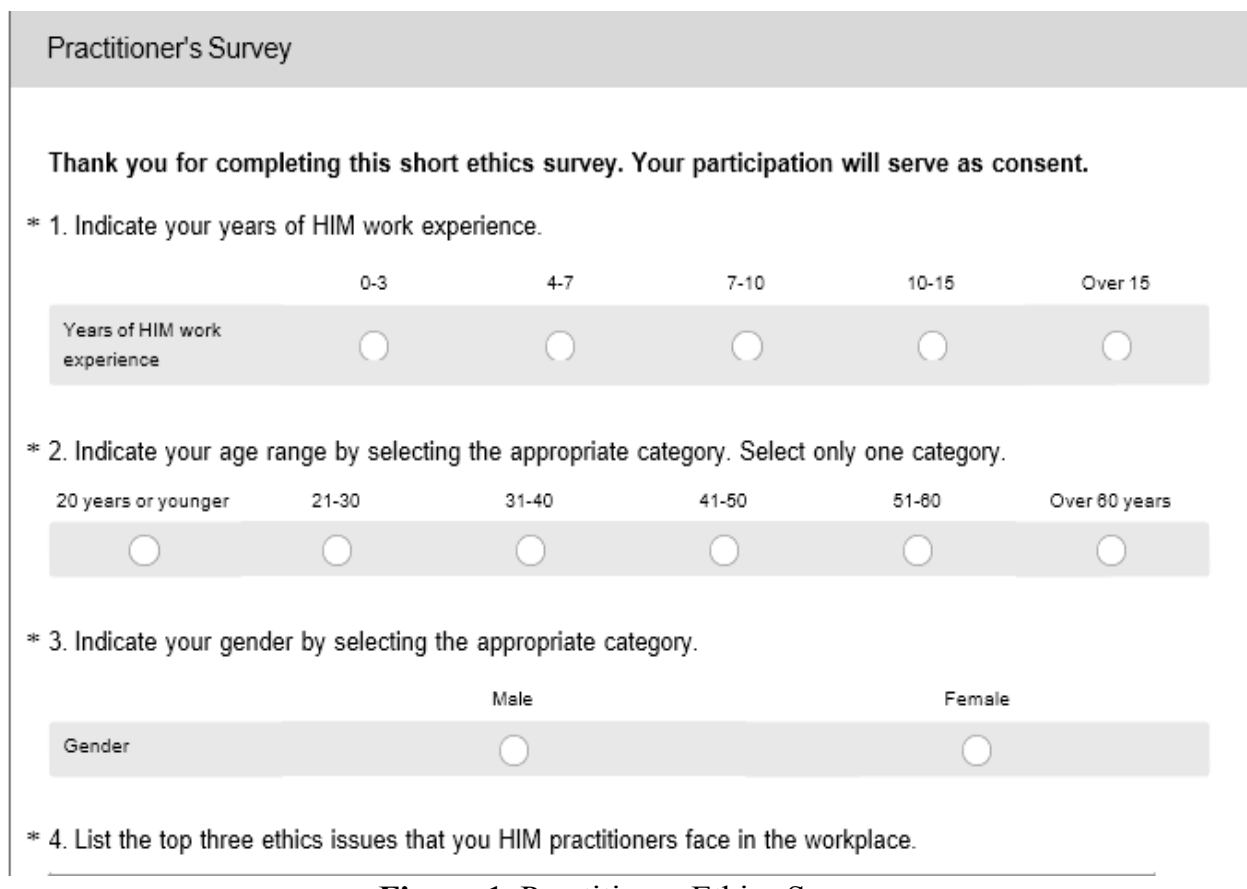

Figure 1. Practitioner Ethics Survey 


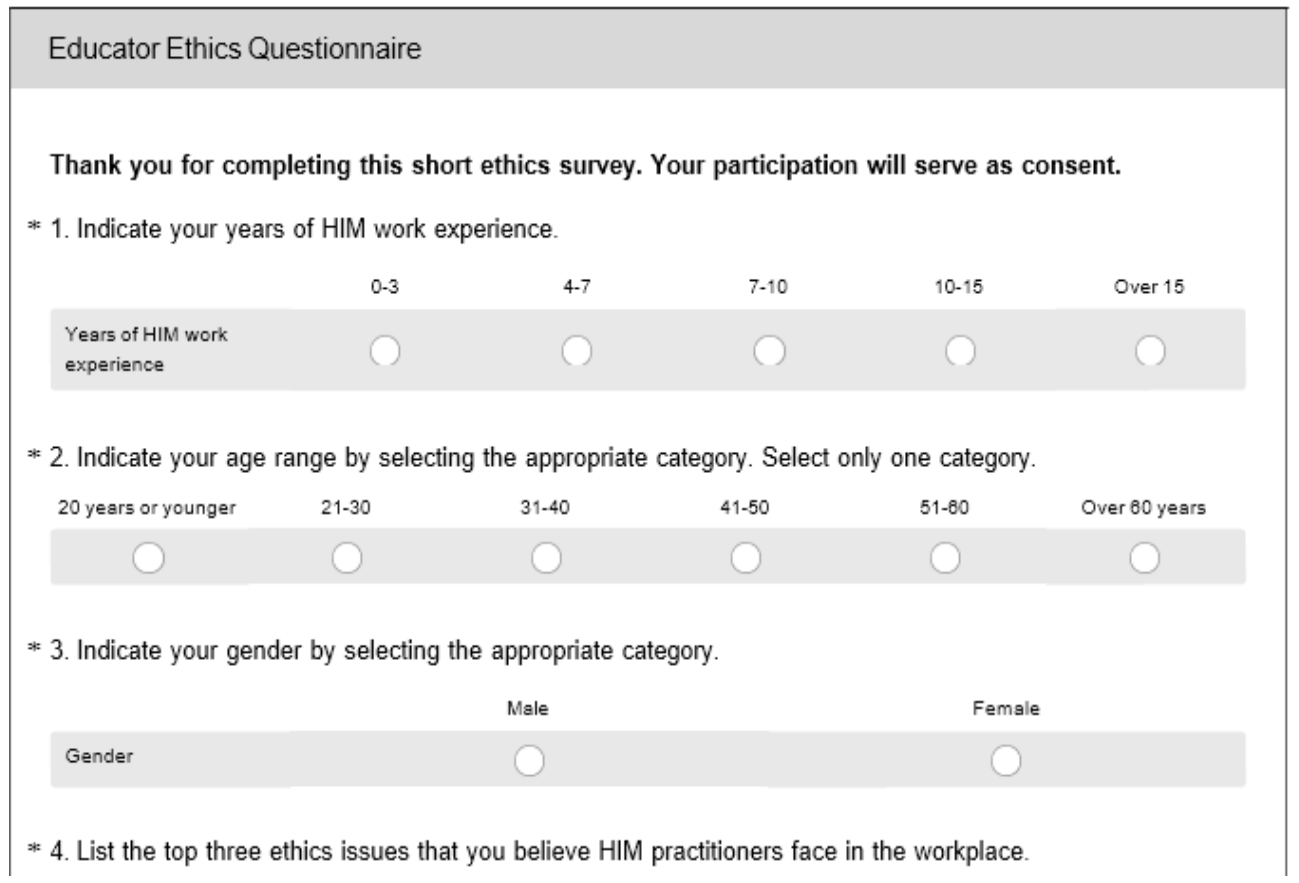

Figure 2. Educator Ethics Survey

The researchers collected data using two web-based, self-constructed surveys. Survey Monkey provided a mechanism for delivering these surveys. Because this was an exploratory study, each survey consisted of three closed demographics questions that indicated age range, gender, and years of HIM work experience. In addition, each survey included one open-ended question inquiring about the participant's (educators and practitioners) view of the top three ethical issues that HIM practitioners face in the workplace. Figures 1 and 2 show the practitioners and the educators' survey questions respectively.

\subsection{Procedures}

The names, and email addresses of the educators $(\mathrm{n}=61)$ were compiled manually into Microsoft Excel. Data cleaning and validation were conducted on the alumni listing $(n=529)$ to remove duplicates, and update information. Using Microsoft Outlook, the researchers created a mail contact list for each group.

All members of both educator and practitioner mail groups received email cover letters containing an invitation to participate, and a link to the online survey. The researchers informed them that the anonymous survey would take about 20 minutes to complete. The researchers also made the surveys available for six weeks in Survey Monkey. Three weeks after the initial mail out, researchers sent a reminder email to both groups to improve response rates. The researchers did not contact subjects by phone or with US postal mail.

\subsection{Analysis}

There were 12 educators and 25 practitioners who completed the surveys. The researchers analyzed the subjects' survey responses using SPSS to generate descriptive statistics for demographic data. Because this was an exploratory study and the literature did not support the use of a priori coding, the researchers used inductive coding procedure in NVivo (Thomas, 2006). This NVivo inductive analysis included repeated reviews of the data to determine codes and themes.

NVivo provided content analysis for the written responses regarding the top three ethical issues stated by each sample group. NVivo also generated word frequency counts for both sample groups. The authors chose the top ten most frequent word counts for each group for further analysis. 


\section{Results}

\subsection{Demographics}

The researchers used SPSS to generate a description of sample demographics. For this study, 61 educators and 529 practitioners composed the sample. Twelve educators and 25 practitioners completed the study for a 38 percent completion rate. Educators who responded were mostly female $(n=10)$, with ages ranging from 31-40 $(n=2)$, to over 60 years $(n=3)$. Nine of the 12 educators reported having more than 15 years of HIM experience. Practitioner respondents were predominantly female $(n=22)$ with years of experience ranging from $0-3$ years $(n=8)$ to over 15 years $(n=9)$. The majority of the practitioners were 21-30 years $(n=7)$, and the next largest range was $41-50$ years $(n=6)$. Table 2 presents the demographic data.

Table 2. Demographic Data

\begin{tabular}{lll}
\hline Demographics & $\begin{array}{l}\text { HIM Program Chairs } \\
(\mathrm{n}=61)\end{array}$ & $\begin{array}{c}\text { HIM Practitioners } \\
(\mathrm{n}=529)\end{array}$ \\
\hline $\begin{array}{l}\text { Participants } \\
\text { Gender }\end{array}$ & 12 & 25 \\
$\quad$ Male & 2 & 3 \\
$\quad$ Female & 10 & 22 \\
Age $\quad$ 20 years or younger & 0 & \\
$21-30$ & 0 & 0 \\
$31-40$ & 2 & 7 \\
$41-50$ & 4 & 4 \\
$51-60$ & 3 & 6 \\
Over 60 years & 3 & 5 \\
Years of HIM Experience & & 3 \\
$0-3$ & 0 & \\
$4-7$ & 0 & 1 \\
$7-10$ & 0 & 2 \\
$10-15$ & 3 & 5 \\
Over 15 & 9 & 9 \\
\hline
\end{tabular}

\subsection{Data Analysis}

To identify patterns and to develop themes, classical content analysis was conducted on the educator and practitioner datasets (Leech \& Onwuegbuzie, 2011). To explore the data in NVivo, the researchers created a project, imported the Excel datasets into the project, and ran an initial query to determine the word frequency for each dataset. For each dataset, they selected the top 10 most frequently used words for theme exploration. Each theme formed the basis for a text query to search and code the data for that theme and the results were stored in thematic tree nodes (Ozkan, 2004).

For example, the word "information" was a commonly occurring word in practitioner data, thus a query searched the practitioner Excel data file for the word "information." The results were saved in a node in NVivo for future analysis. Note that in this software, a respondent's comment could appear in several themes because NVivo uses text pattern matching to locate words. Therefore, a hypothetical respondent comment stating he or she had "concerns about patient data being used for fraud" could be included in patient, data, and fraud themes. Figure 3 provides a schematic of the data analysis process used in NVivo. 


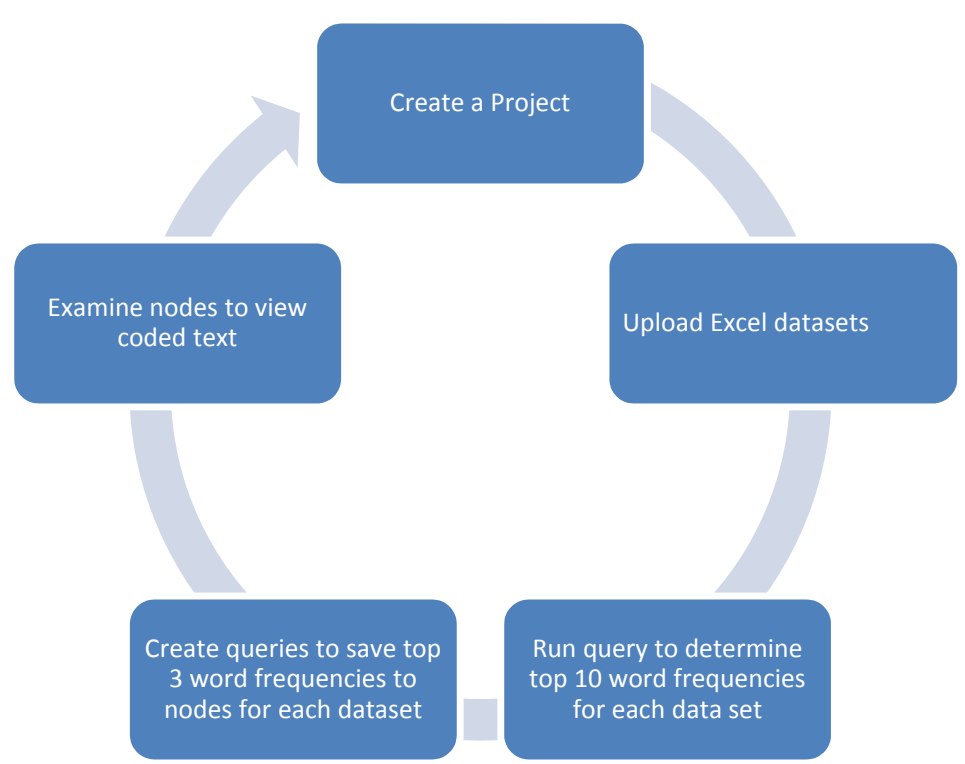

Figure 3. Data Coding in NVivo

Themes for educators were also determined through this query method. Figure 4 shows the top ten themes addressed by the educators with frequencies. The three most commonly reported themes were codding, practices, and reimbursement.

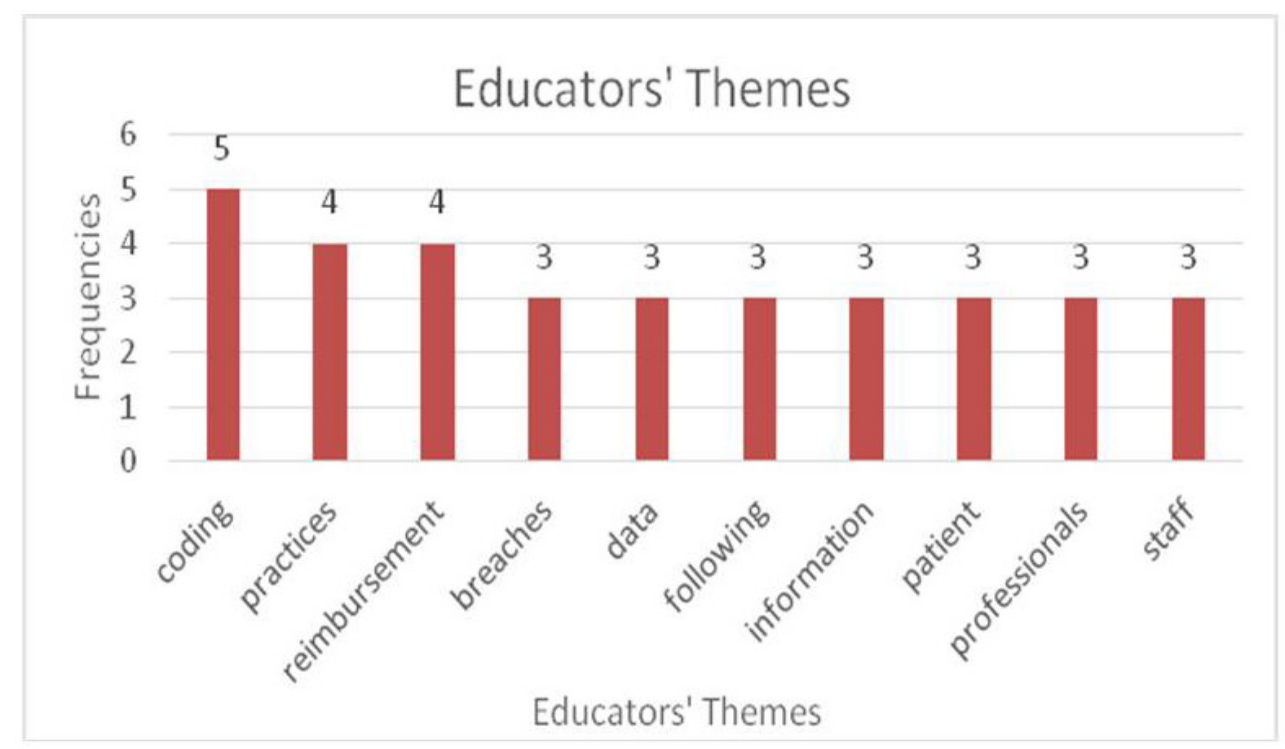

Figure 4. Educators' Themes

Figure 5 presents the most common themes cited by practitioners. The most commonly cited themes among this group had identical frequency counts. These comment themes represented information, patient, and record areas. 


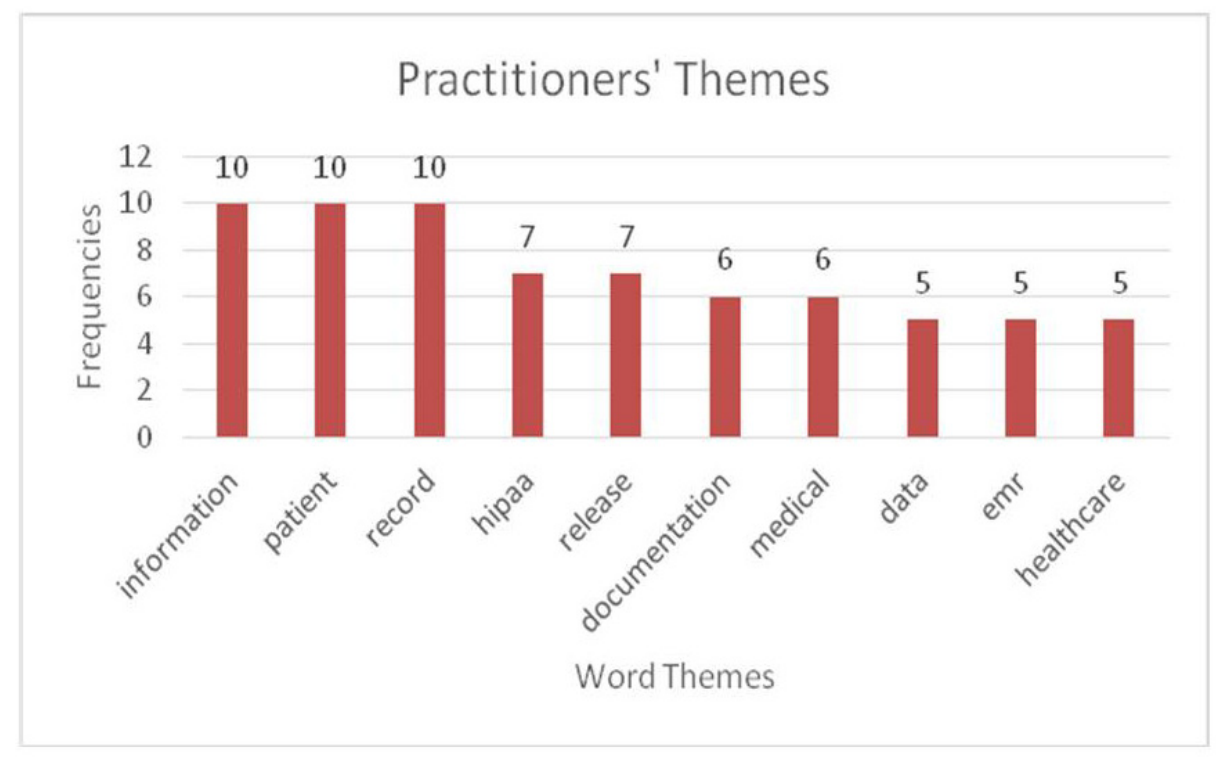

Figure 5. Practitioners' Themes

\section{Discussion}

The review of literature provided a foundation for this study. The review began with the connection between ethics theory and principles and the practice of healthcare decision-making (AHIMA, 2014; Harmon \& Cornelius, 2015; Layman, 2008). The authors also explored the need to understand how ethics applies to decision-making in health care situations (Oachs \& Watters, 2017), which created an interest in determining more specific information related to HIM. The literature review also raised concerns about the congruence between ethics issues faced by practitioners and information presented by faculty. In addition, Budinger \& Budinger's (2006) description of ethics issues concerning privacy and confidentiality and studies conducted with other healthcare professionals reinforced the need to understand ethical issues in the practice of HIM.

Cellucci et al. (2011) suggested that ethics and its application should be a part of the IS curriculum and it should include the application of ethics in the workplace. They discussed the use of real world examples as part student learning in this field. However, given the ever-changing healthcare environment, making appropriate ethical decisions is not a simple task in HIM. Therefore, this study attempted to determine if areas of ethics that educators view as important are consistent with those held by practitioners in the field.

This study supports the findings of Anderson (2004) when he recommends that students practice moral reasoning using situations that occur in the practice of health information management. Moreover, the AHIMA Code of Ethics (American Health Information Management Association, 2015) identifies HIM professions as guardians of personal information and confidentiality of records. This responsibility suggests that HIM educators provide students with opportunities to practice ethical reasoning that better equips them to meet their responsibilities as health information professionals.

To provide appropriate and timely examples for increasing students' moral reasoning ability, faculty must use examples that reflect real world situations. This study served as a starting point for identifying the congruence or lack of congruence between faculty and practitioners' perceptions of major ethics issues. Because this was an exploratory study, the return rate was not high. However, it did meet the researchers' goal of establishing preliminary data and areas for future study. A discussion of the implications of this study by research questions follows.

4.1 Research Question 1-What are the major ethics issues for health information management as perceived by HIM practitioners?

The top three ethical themes reported by HIM professionals in the workplace are information, patient, and record. However, because of the method used to capture themes, these words did not mean the same thing for each practitioner. For example, under the theme of information, practitioners included comments like "...release of Information (when there is proper identification but the employee doesn't feel right releasing)" and " $\ldots$ being understaffed in performing release of information in a timely manner." 
The theme patient as used by practitioners tended toward a connection to confidentiality, privacy, and patient safety. For example, some comments included in this area were: "Patient confidentiality (HIPAA)..." and "accurate medical record documentation especially with the wide use of 'copy and paste technology' that is available in most Electronic Medical Record systems."

For practitioners, the theme of record referred to the medical record, and ethical issues involved printing, copying, and accessing records by patient. Typical comments were "insuring compliance education of hospital staff. To this day, we still get questions from hospital staff as to why they cannot print off their record (i.e., meaning they have already viewed it without appropriate permission)." Another example was "...consistently teaching clinical members the appropriateness vs. inappropriateness of documentation standards for the legal medical record (fighting the pencil whip)."

4.2 Research Question 2-What are the major ethics issues for health information management as perceived by HIM educators?

The top three ethical issues reported by HIM educators were coding, practices, and reimbursement. Again, using the NVivo approach with themes allowed differences in comments about theme areas. For example, when educators discussed coding they were concerned about fraudulent or inaccurate coding. Sample comments included "...fraud and abuse through inaccurate coding," and "... use of personal mobile devices or Internet causing cyber security breaches."

Educators conceptualized unethical practices in terms of fraud, not using documented best practices, and failing to update policies and procedures. Comment examples included discussions of "Fraudulent coding and billing practices in areas not supervised by HIT/HIM professionals" and "not staying current with education on laws and Federal guidelines."

4.3 Research Question 3-What are the differences in perceptions of major health information ethics issues between HIM practitioner and educators?

Although both educators and practitioners mentioned the themes information, patient, and data, there were many differences. Figure 6 provides a comparison of the educators' top themes by word frequency to the practitioner's word frequencies for the same themes. For example, the educators frequently recorded the term professional, but practitioners did not. Similarly, educators mentioned staff ethical issues but practitioners did not report it as a major concern.

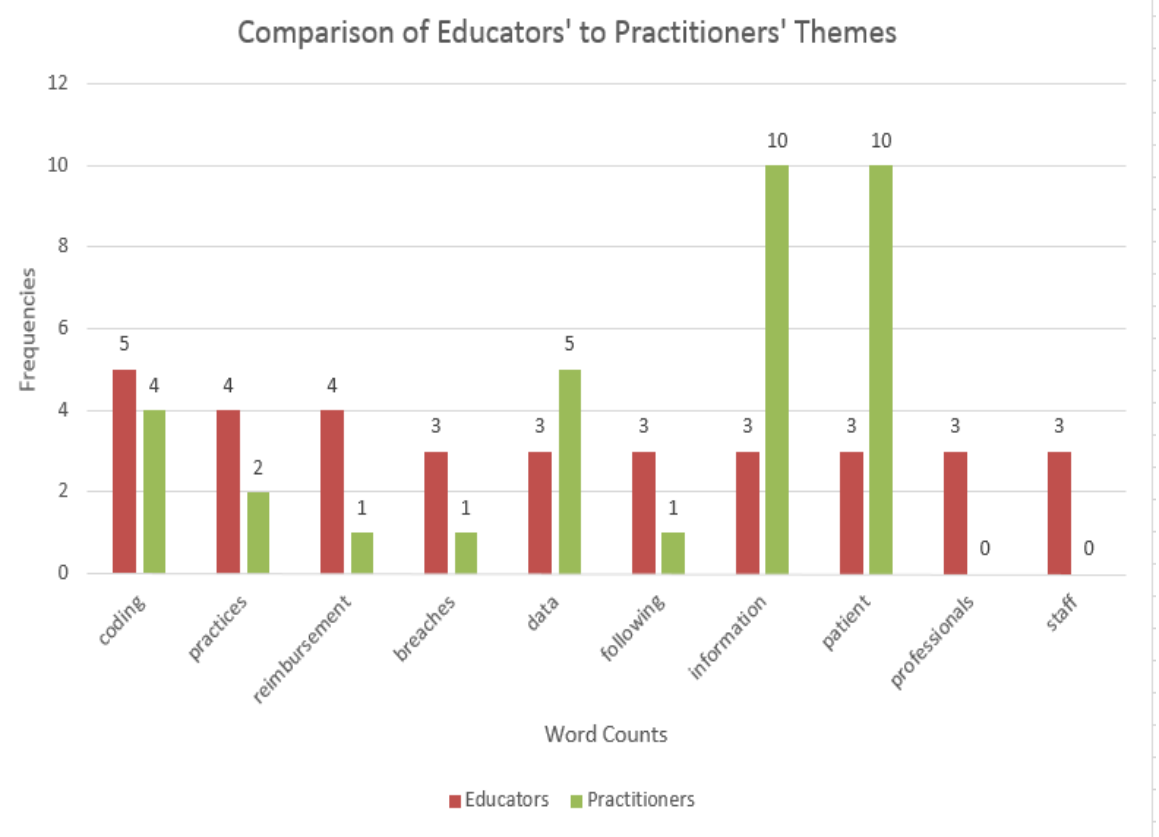

Figure 6. Comparison of Themes 
The themes of patients and information showed the most differences between the educators and the practitioners, with 10 practitioners citing these areas to only three of the educators. In addition, the comments of the educators reflected knowledge areas where the practitioners' comments tended to be more specific in terms of examples of ethics concerns.

Figure 7 is a word cloud generated by the NVivo analysis of this study. It serves as a summary of the study finding and graphically shows the most frequently cited themes through the size of the print. The word cloud further demonstrates the variety of data of themes determined in this study. This figure also suggests that there is more study needed to clarify ethics issues in HIM practice.

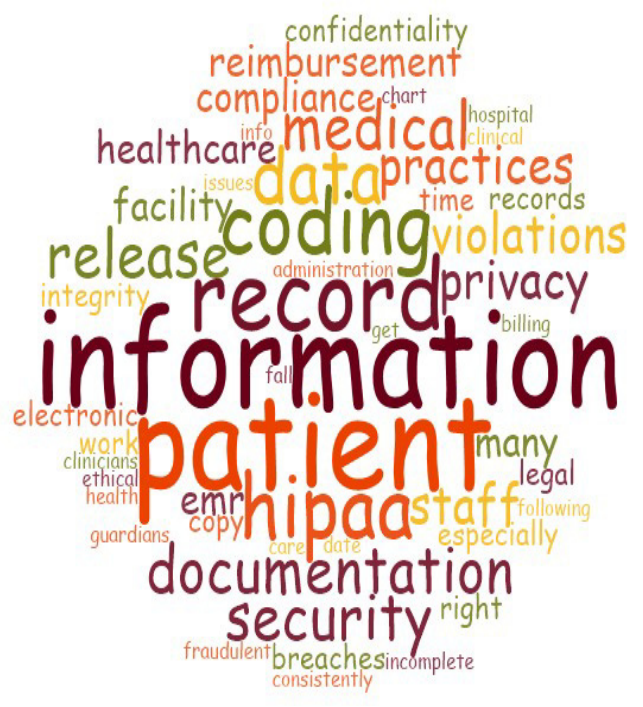

Figure 7. Word Cloud of Educators' and Practitioners' Data

\section{Conclusion}

This exploratory study provides information to continue exploring applied ethics in HIM. Given the disparity of themes, there are differences in the way educators and practitioners view ethical issues. Of course, studies with a larger sample size could help to discern the nature of the differences and add to the body of knowledge in the field. In addition, future studies could provide detailed information on experiences with ethical issues in the workplace by using focus groups of practitioners. Educators could use this additional information for curriculum assessment and improvement by strengthening compliance with sub domains related to ethics. See Figure 1.

The findings of this study also suggest a need for dialogue concerning ethics in the practice of HIM. For example, educators may wish to utilize conferences with their students' preceptors to learn more about their current ethics challenges. The addition of questions about ethical challenges in the preceptor reports could also prove useful for curriculum improvement.

As creators of future HIM practitioners, educators care about how they prepare their students to meet ethical challenges in the ACA era and beyond. Because they care, faculty needs to maintain currency on ethical challenges that will be a part of their students' future. Findings in this exploratory study indicate the advantages for communication between educators and practitioners concerning ethical issues in HIM practice. This communication could provide answers to the question, "What should we be teaching our students about ethics?"

\section{References}

AHIMA House of Delegates. (2008, September). AHIMA standards of ethical coding. Retrieved from http://bok.ahima.org/doc?oid=106344\#.WBNriPkrlcs

AHIMA Professional Ethics Committee. (2013). Reality Check 2013: Ethical Issues in HIM. Journal of AHIMA. Retreived from http://journal.ahima.org/2013/10/01/reality-check-2013-ethical-issues-in-him/.

American Health Information Management Association. (2010). Ethical standards for clinical documentation improvement

$(C D I)$

professionals.

Retrieved

from 
http://library.ahima.org/xpedio/groups/public/documents/ahima/bok1_047842.hcsp?dDocName=bok1_047842

American Health Information Management Association. (2011). American Health Information Management Association code of ethics. Retrieved from http://bok.ahima.org/doc?oid=105098

American Health Information Management Association. (2014). Pocket Glossary of Health Information Management and Technology (4th ed.). Chicago, Illinois: AHIMA Press.

Anderson, J. G. (2004). The role of ethics in information technology decisions: A case-based approach to biomedical informatics education. International Journal of Medical Informatics, 73(2), 145-150. http://dx.doi.org/10.1016/j.jimedinf.2003.11.015

Aulisio, M. P. (2016). Why Did Hospital Ethics Committees Emerge in the U. S.? AMA Journal of Ethics, (5), 546-553. http://dx.doi.org/journalofethics.2016.18.05.mhst1-1605

Budinger T. F., \& Budinger M. D. (2006). Ethics of Emerging Technologies: Scientific Facts and Moral Challenges. Hoboken, NJ: Wiley \& Sons.

Buelow, Janet R, Mahan, Pamela L, \& Garrity, April W. (2010). Ethical Dilemmas As Perceived By Healthcare Students with Teaching Implications. Journal of College Teaching \& Learning, 7(2), 85-92. http://dx.doi.org/10.19030/tlc.v7i2.92

Cellucci, L. W., Layman, E. J., Campbell, R., \& Zeng, X. (2011). Integrating healthcare ethical issues into IS education. Journal of Information Systems Education, 22(3), 215-224.

Cheshire, W. P. (2014). Can Electronic Medical Records Make Physicians More Ethical? Grey Matters, 30(3), 135-141.

Commission on Accreditation for Health Informatics and Information Management Education (CAHIIM) (2016). CAHIIM program directory. Retrieved from http:/www.cahiim.org/directoryofaccredpgms/ programdirectory.aspx

Crawford, M. (2011). Everyday ethics. Journal of AHIMA, 82(4), 30-33.

Dahnke, M. D. (2013). Ethics and the image of the healthcare administrator in popular culture. International Journal of Healthcare Management, 6(3), 177-183. http://dx.doi.org/10.1179/2047971913y.0000000043

Grady, C., Danis, M., Soeken, K., O'Donnell, P., Taylor, C., Farrar, A., \& Ulrich, C. (2008). Does ethics education influence the moral action of practicing nurses and social workers? American Journal of Bioethics, 8(4), 4-11.

Green, S. B., \& Salkind, N. J. (2013). Using SPSS for Windows and Macintosh (6th ed.). Upper Saddle River, NJ: Pearson.

Harman, L. B., \& Cornelius, F. H. (2015). Ethical health informatics (3rd ed.). Burlington, MA: Jones \& Bartlett.

HIMSS. (2016). Ethical Issues in the Use of Health Information. Retrieved from http://www.himss.org/ethical -issues-use-health-it

HIMSS. (2011). Security of mobile computing devices in the healthcare environment. Retrieved from http://www.himss.org/security- mobile-computing- devices-healthcare-environment

HIPAA. (1996). Health Insurance Portability and Accountability Act of 1996. In Public Law, 104-191

IBM Corp (2016). IBM SPSS Statistics for Windows (Version 24) [Computer Software]. Armonk, NY: IBM Corp.

Layman, E. J. (2008, April-June). Ethical issues and the electronic health record. The Health Care Manager, 27(2), 165-176. http://dx.doi.org/10.1097/01.HCM.0000285044.19666.a8

Leech, N. L., \& Onwuegbuzie, A. J. (2011). Beyond constant comparison qualitative data analysis: Using NVivo. School Psychology Quarterly, 26(1), 70-80. http://dx.doi.org.libproxy.txstate.edu/10.1037/a0022711

Lieneck, C. H. (2014). Technology Advances in Health Care: Blessing or Ethics Nightmare. In E. E. Morrison \& B. Furlong (Eds.), Healthcare ethics: Critical issues for the 21st century (3rd ed.). (pp. 259-276). Burlington, MA: Jones and Bartlett Learning.

McWay, D. C. (2016). Legal and Ethical Aspects of Health Information Management (4th ed.). Clifton Park, NY: Cengage Learning.

Monteverde, S. (2014). Undergraduate healthcare ethics education, moral resilience, and the role of ethical theories. Nursing Ethics, 21(4), 385-401. http://dx.doi.org/10.1177/0969733013505308 
Oachs, P. K., \& Watters, A. L. (2016). Health Information Management Concepts, Principles and Practice. Chicago: IL: AHIMA.

Ozkan, B. C. (2004). Using NVivo to analyze qualitative classroom data on constructivist learning environments. The Qualitative Report, 9(4), 589-603.

Patient Protection and Affordable Care Act, 42 U.S.C, 18001 (2010). Retrieved from http://housedocs.house.gov/energycommerce/ppacacon.pdf

QSR International Pty Ltd. (2012). NVivo qualitative data analysis Software (Version 12) [Computer Software]. Doncaster, Victoria: QSR International Pty Ltd.

Thomas, D. R. (2006). A general inductive approach for analyzing qualitative evaluation data. American Journal of Evaluation, 27(2), 237-246. http://dx.doi.org/10.1177/1098214005283748

Ulrich, C. M., Zhou, Q. P., Hanlon, A., Danis, M., \& Grady, C. (2014). The impact of ethics and work-related factors on nurse practitioners' and physician assistants' views on quality of primary healthcare in the United States. Applied Nursing Research, 27(3), 152-156. http://dx.doi.org/10.1016/j.apnr.2014.01.001 